\title{
Envy at Workplace: Examining its Sequential Effect on Cyberbullying, Organizational Politics and Job Satisfaction in University Teachers in Pakistan
}

\author{
Sania Zahra Malik ${ }^{1}$, Jahanzaib Ismat Malhi ${ }^{2}$
}

\begin{abstract}
Academic jealousy and politics is a well-known concept. Similarly, envy is a common human behaviour, however, research on these concepts, particularly on envy and its types has remained limited until recently. Envy can trigger harmful behaviours, such as workplace bullying and escalate political activity, especially when the envious intends to damage the envied. This study analyses the effect of malicious envy on job satisfaction with mediation of cyber bullying and organizational politics. A survey study of 359 questionnaires filled by university teachers in Pakistan was conducted. Analysis was conducted using structural equations modelling through Smart-PLS. Construct validity and discriminant validity were established for all constructs. Mediation was analysed through process approach specified by Preacher and Hayes (2006). Findings revealed that malicious envy positively influenced cyberbullying behaviour and increased organizational politics. Results also demonstrated that malicious envy at workplace does not affect job satisfaction when observed independently, however when the mediators of cyberbullying and organizational politics are involved, the relationship between malicious envy and job satisfaction becomes positive. It means that persons having malicious envy feelings towards their colleagues felt satisfied by engaging in bullying and politicizing activities.
\end{abstract}

Keywords: Malicious envy, Cyber bullying, Organizational politics, Job satisfaction

\section{Introduction}

There are many antecedents and sources of anger and aggressive behaviours, such as role conflict, lack of trust, perception of justice, and many more (Trépanier et al., 2016). An important dynamic which prevails extensively in all human communities, and giving rise to negative feeling and behaviours, is envy. Envy is a particular obstructive outcome of social and electronic media.

\footnotetext{
${ }^{1}$ Assistant Professor, Institute of Business Administration, University of the Punjab, New Campus, Lahore, Email: saniazmalik@ibapu.edu.pk

${ }^{2}$ Research Scholar, Institute of Business Administration, University of the Punjab, New Campus, Lahore, Email: jim.edu.pk@gmail.com
} 
Envy is simply the desire of acquiring a possession belonging to some other person. Envy could be so detrimental that it can seriously reduce the morale and performance of the employees and also lead towards resignation from the post (Falcon, 2015). Although envy has existed in human societies since times immemorial, its conceptualization and dynamics have come under recent scrutiny in organizational behaviour literature (Lee \& Duffy, 2019).

Social media platforms such as Facebook, WhatsApp, Twitter etc. that provide opportunity to workplace members, formal and informal to interact smoothly have changed dynamics of communication in the workplace. All such applications have become an integral part of workplace as they are not just being used for entertainment purposes rather have also been used for official work (David \& Janani, 2011). Workplace requires a lot of information to be shared among the employees for effective working and hence electronic media plays an integral role for sharing information through cyberspace (Hershcovis, 2011). Cyberspace simply can be described as a space or environment where transmission of information transpires through digital web works. Cyberspace is an integral part of the workplace as all the information and important documents relevant to the employees and customers can be transmitted with ease (Clarke, 2001).

Literature suggests that current academic debates are focused on evaluating the importance and impact of negative and antisocial deviant behaviours such as workplace bullying, abusive responses, workplace politics, negative treatment of employees and peer group on organization and individuals (Einarsen, 1999; Kabat-Farr, 2018). While cyber space and social media forums are being employed for effective communication and good governance, there is also a rising trend of these forums being used for destructive behaviors. Thus, when acts of bullying are committed on the cyber space, such specific electronic actions are termed as cyberbullying (Smith, 2012). Therefore, the primary objective of this study is to explore the relationship of envy, particularly malicious envy with cyberbullying behaviours and find out how it leads to employees' job satisfaction specifically in teachers working in universities of Pakistan.

It is also well-known that organizational politics is a pervasive phenomenon. Politics means the power struggles prevailing at workplace where employees engage in influence and pressure tactics to achieve vested gains and interests, which cannot be obtained through normal work procedures (Ferris et al., 2008). Envy is a feeling which is directed towards the envied with various intentions. Particularly, malicious envy is a type of envy in which the envier attempts to harm the envied by snatching away possession of the envied object 
(Lange, et al., 2018). We expect to see escalated organizational politics as direct result of malicious envy as well as through the indirect effect of increased cyber bullying.

Therefore, to summarize, the problem statement of study is to find the association between malicious envy and cyber bullying, cyber bullying and organizational politics, and organizational politics with job satisfaction. Underpinning of this research is based on the excessive exploitation of social media that triggers envious behaviour of an individual which may lead towards cyber bullying. Cyber bullying is basically a crime which may generate organization politics within the workplace and towards specific work group. With the increase of organizational politics, job satisfaction of employees gets reduced which may lead towards high turnover.

\subsection{Objectives of Study}

From the problem statement, the following objectives of the study have been enlisted;

1. To measure the level of malicious envy, cyber bullying, organizational politics and job satisfaction among university teachers in Pakistan.

2. To find the association of malicious envy with cyber bullying, organizational politics, and job satisfaction.

3. To evaluate if cyberbullying and organizational politics sequentially mediates the relationship between malicious envy and job satisfaction.

\subsection{Hypotheses of Study}

$\mathrm{H}_{1}$ : There exists a negative relationship between malicious envy and job satisfaction.

$\mathrm{H}_{2}$ : There is a positive relationship between malicious envy and cyber bullying

$\mathrm{H}_{3}$ : There is a positive relationship between malicious envy and organizational politics.

$\mathrm{H}_{4}$ : Cyber bullying and organizational politics sequentially mediate the relationship between malicious envy and job satisfaction.

\section{Literature Review}

Malicious envy is regarded as a negative emotion where the envious wishes and is motivated to bring down the envied. Many previous researches mixed the terms of resentment as well as malicious envy whereby Van de Ven et al. (2009) distinguished both terms and identified that resentment is a destructive emotion such that the resentful one focuses on bringing down the resented whereas malicious envy is a destructive emotion such that the envious focuses on degrading the envied as well as uplifting itself from others. Malicious envy involves activating the inferiority complex which is absent in resentment (Smith, 2000). Malicious envy requires the culprit to arouse the feeling that the target 
possessing a specific quality, attribute or skill to be lost as it is not in the possession of the culprit (Van de Ven et al., 2009). Recently, it has been suggested that malicious envy comprises of three essential elements, i.e. inferiority complex, hostility, resentment (Lange, et al., 2018). Malicious envy is much worse than benign envy. It is one of the most adverse mental states that commonly prevails in the work environment (Tai et al., 2012).

Employees satisfied with their job possess and spread positive energy at workplace. Competitive reward systems that prevail at the workplace are likely to engage employees towards envious behaviour. When a person is deprived of some recognition, rewards and awards, envy is a possible outcome towards those on whom these things are being bestowed (Masclach et al., 2001). Unequal and uneven distribution of rewards at the work place would create the perception of injustice in the mind of employees towards other co-workers which would ultimately lower the job satisfaction level (Saks, 2006). Inequity or lack of fairness prevailing in the organization among various subordinates would lead to dissatisfaction among employees (Saks, 2006). Vecchio (2000) unveiled that the desire to quit the job is triggered by the destructive emotion of envy and jealousy.

Satisfaction is generally described as the feeling that an individual perceives when his/her desires are fulfilled to a considerable extent. There can be no particular exact definition of the general phenomenon of job satisfaction. McPhee and Townsend (1992) described job satisfaction as a positive and delightful feeling, emanating from the perception of an individual's job relevant to the attainment of one's compulsory job values, contributing towards the compatibility of the values with the psychological and physical desires.

Malicious envy mostly leads to stress which lowers the satisfaction level of an employee towards his/her organization. Malicious envy enhances the social interaction but in a negative way which may lead to stress and burden on the employee and may lead to lower morale by ultimately reducing job satisfaction level (Rich et. al., 2010). Erdila and Müceldili (2014) conducted a study in turkey and identified the negative impact that malicious envy has on job satisfaction, turnover intention and job involvement. Therefore, this study proposes the following primary hypothesis;

Bullying is an unethical behavior occurring in those organizations where bullies or culprit feel safe and is able to make a tougher climate for the victim while promoting organizational politics (Einarsen, 1999). Cyberbullying is termed as "an aggressive, intentional act carried out by a group or individual, using electronic forms of contact, repeatedly and over time against a victim who cannot easily defend him or herself" (Smith et al., 2008). Bullying such as victimization, workplace aggression, employee abuse or mobbing have been 
investigated by various researchers that have negative impact on employees wellbeing as well as organizational performance (Einarsen \& Mikkelsen, 2002). Envious behavior of an employee may lead to work place bullying and cyber bullying such as threat of physical violence, humiliation in public (yelling and criticizing for no reason), social isolation, attacking the personal life of the victim by ridicule and insulting remark and behaviours to find faults in the work of the envied (Zapf,1999).

Workplace politics is a part of every organization, which can be beneficial for employees in the form of collective rewards, protection of employees' benefits, project approvals, etc. However, there is also a dark side of dynamics of organizational politics. Several studies indicate that there are many negative effects of organizational politics on individual perceptions and attitudes including reduced job satisfaction and organizational commitment, increased stress and turnover intentions, and reduced performance (Miller et al., 2008).

One of the major factors that cause envy in organizations is the scarcity of resources (Cohen-Charash, 2009) At the same time, where resources are limited, the power struggle to gain access to the few resources (monetary, facilities, technology, rewards) increases, and therefore, causes escalated politics (Drory \& Romm, 1990). Also, envy is triggered in an environment where perceived fairness and justice is low (Demirtas, et al., 2017). Increased organizational politics also leads to unequal distribution of resources and victimization (Amponsah-Tawiah \& Annor, 2017). Therefore, it can be expected that malicious envy would lead to increased organizational politics.

While malicious envy has a direct link with all the above mentioned phenomenon, we also expect that there will be step-wise, serial and compounding effect of malicious envy. Intention to harm and remove the object of envy from the envious is an inherent part of malicious envy (Lange, et al., 2018). It is expected that this intention to inflict harm or injury (physical or psychological) will lead to aggressive and victimizing behaviours, which may also include cyber bullying, which will in turn lead to escalated organizational politics. Bullying may become such an ingrained phenomenon of an organization that new managers and employees entering the workplace see it as a workplace norm (Robinson \& O'Leary-Kelly, 1998). Similarly, organizational politics also influences behaviors, attitudes, feelings and emotions of employees at workplace. A number of studies demonstrated a negative and indirect link between organizational politics and job satisfaction (Ferris et al., 1989; Ferris \& Kacmar, 1992; Gandz \& Murray, 1980). 


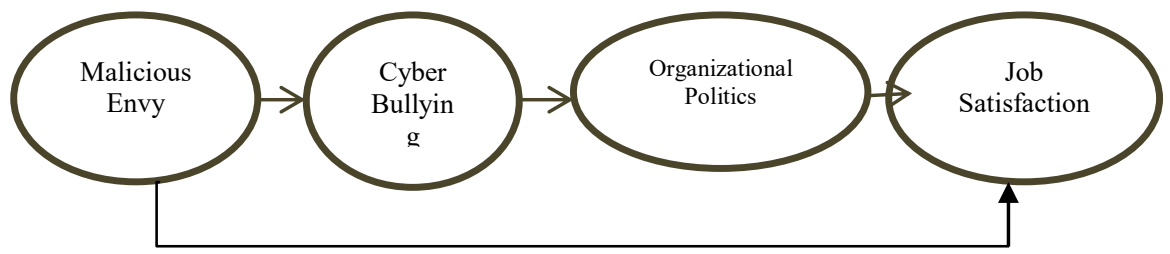

Figure 2.1. Schematic diagram

\subsection{Research Design}

\section{Research Methodology}

A survey methodology employing quantitative techniques has been adopted. Such research design uses techniques that eliminates the threat of biasness and enhances the generalizability of the results to the entire population.

\subsection{Population of the Study}

University teachers working in the public and private sector universities of Pakistan is the population of this study.

\subsection{Sample \& Sampling Technique}

Teachers working in two public and two private sector universities of Pakistan were approached through convenient sampling technique.

\subsection{Instrumentation}

A 38 item scale has been adapted by the researcher to elicit employees' response towards malicious envy, cyber bullying, organizational politics and job satisfaction. The response format of items included in the questionnaire was a seven-point Likert scale with responses ranging from $7=$ strongly agree to $1=$ strongly disagree. The items used in the questionnaire were adapted from the sources listed in Table 1.

Table 3.4

\begin{tabular}{ll} 
Measures & \\
\hline Construct & Source \\
\hline Malicious Envy & Lange et al. (2018) \\
Cyber Bullying & Farley et al. (2016) \\
Organizational Politics & Kacmar \& Carlson (1997) \\
Job Satisfaction & Spector (2014) \\
\hline
\end{tabular}

\subsection{Reliability and Validity}

A detailed and rigorous method was adopted to ascertain the validity and reliability of the measures. For the estimation of the proposed structural model, Smart PLS-SEM has been employed. In order to establish reliability and validity of the instrument the researcher requires calculating Cronbach's alpha or 
composite reliability (CR), average variance extracted (AVE) and heterotraitmonotrait (HTMT) ratio. PLS-SEM calculates CR, AVE and HTMT ratio using PLS-Algorithm procedure. Following table shows the calculated values of Factor Loadings, CR and AVE.

Table 3.5

Factor loadings, CR and AVE of constructs

\begin{tabular}{|c|c|c|c|}
\hline Items & Factor Loading & $\mathrm{CR}$ & AVE \\
\hline Cyber Bullying & & 0.911 & 0.40 \\
\hline CB-1 & 0.631 & & \\
\hline CB-10 & 0.615 & & \\
\hline CB-11 & 0.642 & & \\
\hline CB-12 & 0.560 & & \\
\hline CB-13 & 0.404 & & \\
\hline CB-14 & 0.597 & & \\
\hline CB-15 & 0.556 & & \\
\hline CB-16 & 0.678 & & \\
\hline CB-17 & 0.652 & & \\
\hline CB-2 & 0.705 & & \\
\hline CB-3 & 0.701 & & \\
\hline CB-4 & 0.685 & & \\
\hline $\mathrm{CB}-5$ & 0.682 & & \\
\hline CB-6 & 0.679 & & \\
\hline CB-7 & 0.487 & & \\
\hline CB-8 & 0.416 & & \\
\hline CB-9 & 0.669 & & \\
\hline Malicious Envy & & 0.852 & 0.59 \\
\hline ENV-1 & 0.816 & & \\
\hline ENV-2 & 0.762 & & \\
\hline ENV-3 & 0.767 & & \\
\hline ENV-4 & 0.727 & & \\
\hline Job Satisfaction & & 0.823 & 0.40 \\
\hline JS-1 & 0.598 & & \\
\hline JS-2 & 0.662 & & \\
\hline JS-3 & 0.554 & & \\
\hline JS-6 & 0.627 & & \\
\hline JS-7 & 0.692 & & \\
\hline JS-8 & 0.684 & & \\
\hline
\end{tabular}




\begin{tabular}{llll}
\hline JS-9 & 0.604 & 0.820 & 0.40 \\
Organizational Politics & & & \\
OP-1 & 0.598 & \\
OP-2 & 0.662 & \\
OP-3 & 0.554 & \\
OP-4 & 0.627 & \\
OP-5 & 0.692 & \\
O-P6 & 0.684 & \\
\hline
\end{tabular}

The computed value of CR and AVE ought to be higher than 0.70 and 0.5 respectively. Moreover, factor loading of each item in a scale is close to 0.60 . The calculated value of factor loading influences the value of CR as well as AVE. The estimated values of CR and AVE in Table 3.5 shows that reliability and convergent validity is appropriate for the scales of Cyber Bullying, Job Satisfaction, Malicious envy, and Organizational Politics. Researchers also calculated discriminant validity using several techniques such as Fornell-Larker and HTMT Ratio. HTMT Ratio considered appropriate for calculating discriminant validity. The discriminant validity established for determinants used in current model (Table 3.6)

Table 3.6

\begin{tabular}{|c|c|c|c|c|}
\hline $\begin{array}{l}\text { Sr. } \\
\text { No }\end{array}$ & Constructs & 1 & 2 & 3 \\
\hline 1 & Cyber Bullying & & & \\
\hline 2 & Malicious Envy & 0.625 & & \\
\hline 3 & Job Satisfaction & 0.192 & 0.196 & \\
\hline 4 & Organizational Politics & 0.546 & 0.249 & 0.248 \\
\hline
\end{tabular}

\subsection{Data Collection}

Survey based on structured questionnaire was distributed among the teachers working in universities in Pakistan. The data were assembled through the survey in public and private universities of Lahore. Four hundred questionnaires were dispersed to different teachers in public and private universities, 359 were included for assessment and others have been discarded due to incomplete, weak and non-serious answering attitudes. Resulting $89.75 \%$ response rate is meritorious for this study.

\section{Data Analysis and Interpretation}

Approximately $50 \%$ of the participants were within the age category of 25-29 years and $75 \%$ respondents were male teachers. Two third of responses 
were given by private sector teachers (approx. 66\%) as compared to one third public sector (approx. 33\%) employees.

Table 4.1

Descriptive statistics of Respondents

\begin{tabular}{llll}
\hline Demographic & Value & Frequency & $\%$ age \\
\hline Gender & Male & 267 & $74.4 \%$ \\
Age & Female & 92 & $25.6 \%$ \\
& $25-29$ & 179 & $49.9 \%$ \\
& $30-34$ & 75 & $20.9 \%$ \\
& $35-39$ & 84 & $23.4 \%$ \\
Status of & 40 years and & 21 & $5.8 \%$ \\
Organization & above & & \\
Social Media Usage & Public & 120 & $33.4 \%$ \\
& Private & 239 & $66.6 \%$ \\
& Yes & 323 & $90 \%$ \\
& No & 35 & $9.7 \%$ \\
& Missing & 1 & $0.3 \%$ \\
\hline
\end{tabular}

Table 4.2 presents the initial correlation values of the variables. The values show that malicious envy, cyber bullying and organizational politics relate with each other significantly $(\mathrm{p}<0.01)$ whereas job satisfaction only moderately relate with organizational politics $(\mathrm{p}<0.05)$ and do not relate with malicious envy or cyberbullying ( $\mathrm{p}>0.05)$.

Table 4.2

Correlation Matrix

\begin{tabular}{rlcccc}
\hline $\begin{array}{c}\text { Sr. } \\
\text { No }\end{array}$ & Constructs & 1 & 2 & 3 & 4 \\
\hline 1 & Organizational Politics & 1 & & & \\
2 & Cyber Bullying & $0.437^{* *}$ & 1 & & \\
3 & Malicious Envy & $0.164^{* *}$ & $0.515^{* *}$ & 1 & \\
4 & Job Satisfaction & $0.121^{*}$ & -0.047 & 0.075 & 1 \\
\hline
\end{tabular}

** Significant at the level of $1 \%$ or 0.01

* Significant at the level of $5 \%$ or 0.05

Smart PLS-SEM Bootstrapping procedure applies to estimate the proposed model. The current study estimates the proposed model using 2000 iterations. SRMR is operated to estimate model fitness and it ranges from $0-1$. The value of SRMR falls within 0-0.08 signifies a perfect model fit. Value of SRMR (0.085) indicating a perfectly fit model, excerpted using Bootstrapping process. 
The results of PLS-Bootstrapping process found that malicious envy has no effect on job satisfaction $(\beta=0.120, p=0.384>0.05)$, therefore Hypothesis 1 is not supported. However, the Figure 4.2 displays that malicious envy has an indirect and circuitous repercussion on job satisfaction employing sequential mediation of cyber bullying and organizational politics. The model extracted indicate a positive and highly significant effect of malicious envy on cyber bullying $(\beta=0.525, p=0.000<0.01)$, supporting Hypothesis 2 . Cyber bullying, in turn, positively influence organizational politics $(\beta=0.505, p=0.000<0.01)$, supporting hypothesis 3 . Finally, the results on sequential mediation show a minor change in job satisfaction $(\beta=0.151, p=0.087<0.10)$ at the level of $10 \%$ significance through the combined effect of malicious envy mediated by cyberbullying and organizational politics, thus supporting hypothesis 4 .

Smart PLS-SEM calculate coefficient of determination, i.e., $\mathrm{R}^{2}$ to estimate variance generated by proposed independent variables on dependent variable within proposed model. Table 4.3 represents the calculated value appertaining to Coefficient of Determination. Researchers not only rely solely on $\mathrm{R}^{2}$, rather, calculate Stone-Geisser $\mathrm{Q}^{2}$ to cross-check the Coefficient of Determination. It is recommended that the estimated amount of $\mathrm{Q}^{2}$ ought to be higher than Zero to authorize anticipating pertinence of the proposed model.

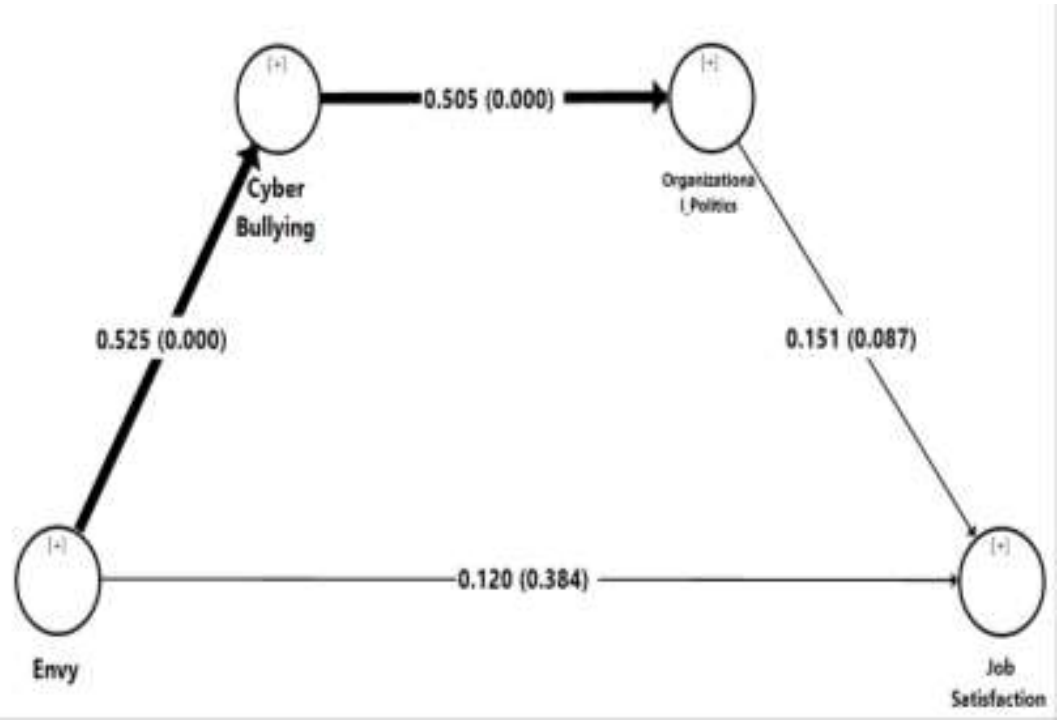

Figure 4.2 Structural Model 
Table 4.3

\begin{tabular}{lccc} 
Values of $R^{2}$ and $Q^{2}$ & & & \\
\hline Constructs & $\mathrm{R} 2$ & $\mathrm{Q} 2$ & Effect \\
\hline Cyber Bullying & 0.276 & 0.096 & Small \\
Job Satisfaction & 0.045 & 0.010 & Small \\
Organizational Politics & 0.255 & 0.082 & Small
\end{tabular}

Small: $0.0<$ Q2 effect size $<0.15$; Medium: $0.15<$ Q2 effect size $<0.35$; Large: Q2 effect size $>0.35$

To further examine mediation, the present study adopts Zhao et al. (2010), Preacher and Hayes (2004) and Shrout and Bolger (2002) technique. They assert that casual-step approach of Baron and Kenny (1986) is not feasible to test mediation due to inappropriate assumption. Instead of casual-step approach, Zhao et al. (2010), Preacher and Hayes (2004) and Shrout and Bolger (2002) technique advised to estimate Variance Accounted For (VAF). VAF refers to degree where indirect effect consumes total effect and it ranges from 0 1. Table 7 displays the estimated amount of Direct, Indirect, Total effect, and VAF.

$$
V A F=\frac{\text { Indirect Effect }}{\text { Total Effect }}
$$

The estimated amount of VAF displays that both cyber bullying and organizational politics indicate partial sequential mediation. Table 7 showing VAF value of 0.25 further confirms support for hypothesis 4 stating the sequential mediation of cyber bullying and organizational politics on the relationship of malicious envy and job satisfaction.

Table 4.4

Mediation Analysis: Cyber Bullying and Organizational Politics as Sequential Mediator

\begin{tabular}{lllllll}
\hline Sr. & Mediation Path & $\begin{array}{l}\text { Direct } \\
\text { Effect }\end{array}$ & $\begin{array}{l}\text { Indirect } \\
\text { Effect }\end{array}$ & $\begin{array}{l}\text { Total } \\
\text { Effect }\end{array}$ & VAF & Mediation \\
\hline \multicolumn{1}{c}{$\begin{array}{l}\text { Malicious Envy- } \\
\text { Cyber Bullying- }\end{array}$} & & & & & \\
1 & $\begin{array}{l}\text { Organizational } \\
\text { Politics-Job } \\
\text { Satisfaction }\end{array}$ & 0.120 & 0.040 & 0.160 & 0.25 & Partial \\
& & & & & \\
\hline
\end{tabular}

No Mediation: $0.0<\mathrm{VAF}<0.20$; Partial Medium: $0.20<\mathrm{VAF}<0.80$; Full Mediation: $0.80<\mathrm{VAF}<1.0$

\section{Discussion \& Conclusion}

The objective of the study was to determine the association between malicious envy and job satisfaction via sequential mediation of cyber bullying 
and organizational politics in university teachers working in Pakistan. The results demonstrated that malicious envy has no direct relationship with job satisfaction $(\beta=0.120, p=0.384>0.05)$. This result is in contrast with the the study of Erdila and Müceldili (2014). However, malicious envy has positive association with cyber bullying and organizational politics which in turn affects job satisfaction. The results of the second hypothesis indicate that the association between malicious envy and cyber bullying $(\beta=0.525, p=0.000<0.01)$ is significant. This hypothesis is supported by the study of De Wet and Jacobs (2013) and Matsela and Kirsten (2014). The results of third hypothesis demonstrate that effect of cyber bullying over organizational politics $(\beta=0.505, p=0.000<0.01)$ is significant. This hypothesis is supported by the study of Zapf \& Warth (1997) and Salin (2002). Finally, results show that the fourth hypothesis proposing the serial mediation of cyber bullying and organizational politics between malicious envy and job satisfaction $(\mathrm{VAF}=0.25)$ is supported and there is partial mediation between the variables.

This study has made a significant contribution in the envy and workplace bullying literature. It has explored a particular type of envy, i.e. malicious envy which is a recently refined concept that distinguishes the darker and harmful type of envy from other types, which are benign envy and pain envy (Lange et al., 2018). Results also demonstrated that it causes signifciant harmful behaviors of cyber bullying which itself is an emerging concept and phenomenon, and also leads to organizational politics, which in many instances has been shown to cause detrimental outcomes of reduced job satisfaction, commitment, productivity and increased turnover intentions (Miller, et al., 2008). Salin (2002) asserts that bullying is an intentional act with the aim to establish, promote and facilitate organizational politics. Workplace bullying is a violent and destructive behaviour towards targeted individual. It may be offline or online. Offline bullying refers to violent behaviour within or outside the office premises. Online bullying is similar to offline bullying with the difference of medium. In online bullying, victim is threatened or faces violent behaviour through the medium of social media such as text messages or through messenger apps e.g., Facebook, WhatsApp, Instagram, etc. Online bullying using social media is termed as cyber bullying.

The political environment in any organization leads to low level of productivity and satisfaction. Based upon the results, this study claimed that individual with the malicious envy mind-set gravitates to be dissatisfied with their job due to the presence of cyber bullying and organizational politics. However, this hypothesis was not supported when direct effect of malicious envy was observed on job satisfaction, however, through the mediation of cyber bullying and organizational politics, the relationship became positive rather than 
negative. This is possible because satisfaction was observed from the perspective of the envier. It is possible that when the sole effect of envying on satisfaction was observed, it was not significant. An envier is neither satisfied nor dissatisfied from his job. However, when the envier mobilizes its malicious envy into cyber bullying and galvanizes organizational politics and targets the envied, it brings the envier a sense of satisfaction. The findings are quite interesting for the workplace envy literature and can be further explored with different settings or methods.

\section{Recommendations}

Emerging from this study, there are potential recommendations for the managers. In this study, it has been shown that malicious envy leads to cyberbullying, which in turns leads to organizatinal politics and reduces job satisfaction, not directly but indirectly.Therefore, it can be inferred that managers can reduce cyberbullying and organizational politics and also manage job satisfaction by reducing malicious envy, according to hypothesis 2,3 and 4 . It is known from literature that envy gets triggered in an environment with the perception of biasness and injustice (Demirtas, et al., 2017).

1. Therefore, managers should try to foster a culture of fairness and equality. This can be achieved by adopting an ethical or authentic leadership style which is perceived by employees to ensure transparency, authenticity and ethics.

2. Organizations should conduct trainings to enhance management styles to reduce the triggering of envy.

3. Moreover, top management and HR manager should conduct special training sessions and workshops to eliminate bullying culture.

4. They should also promote an open and fair environment that eradicates political pressure groups and discourages the establishment of pressure groups. Instead, managers should try to develop positive, enabling and trusting culture.

5. They should work to exclude the factors that cultivate malicious envy mindset among employees such as work overload, role conflict, organizational injustice and many others.

6. At the policy level, cyber laws regarding harassment at workplace should be framed. Currenly, there are cyber crime laws in force in various countries. There are many policies regarding the victims in offline bullying or face to face bullying however no clear policies or agents are available for protecting the victim facing cyber or electronic bullying (Tokunaga, 2010).

7. In Pakistan, Prevention against Electronic Crimes Act (PECA) came in force in August, 2016 which prohibits and punishes offences committed over the 
internet and social media applications in general. However, workplace is a specific area where people spend a significant part of their days and earn their living and build lifetime careers. Therefore, application of cyber crime acts in the domain of workplace harassment and bullying needs specific attention from policy makers.

\section{References}

Amponsah-Tawiah, K., \& Annor, F. (2017). Do personality and organizational politics predict workplace victimization? A study among Ghanaian employees. Safety and Health at Work, 8(1), 72-76.

Clarke, R. (2001). Privacy as a means of engendering trust in cyberspace commerce. UNSW Law Journal, 24, 290-297.

Cohen-Charash, Y. (2009). Episodic envy. Journal of Applied Social Psychology, 39(9), 2128-2173.

David, L. \& Janani, V. (2011). Evaluating a Social Media Application for Sustainability in the Workplace. Vancouver, BC, Canada: California Digital Library, University of California.

Demirtas, O., Hannah, S. T., Gok, K., Arslan, A., \& Capar, N. (2017). The moderated influence of ethical leadership, via meaningful work, on followers' engagement, organizational identification, and envy. Journal of Business Ethics, 145(1), 183-199.

De Wet, C., \& Jacobs, L. (2013). South African teachers exposure to workplace bullying. The Journal for Transdisciplinary Research in Southern Africa, $9(3), 446-464$.

Drory, A., \& Romm, T. (1990). The definition of organizational politics: A review. Human relations, 43(11), 1133-1154.

Einarsen, S. (1999). The nature and causes of bullying at work. International Journal of Manpower, 20(1-2), 16-27.

Einarsen, S. \& Mikkelsen, E. (2002). Individual effects of exposure to bullying at work. In S. H. Einarsen, Bullying and Emotional Abuse in the Workplace: International Perspectives in Research and Practice. London: Taylor \& Francis. 
Erdila, O. \& Müceldili, B. (2014). The Effects of Envy on Job Engagement and Turnover Intention. Procedia - Social and Behavioral Sciences, 150, 447 -454 .

Falcon, R. G. (2015). Is envy categorical or dimensional? An empirical investigation using taxometric analysis. Emotion, 15, 694-698.

Farley, S., Coyne, I., Axtell, C., \& Sprigg, C. (2016). Design, development and validation of a workplace cyberbullying measure, the WCM. Work \& Stress, 30(4), 293-317.

Ferris, G. R., \& Kacmar, K. M. (1992). Perceptions of organizational politics. Journal of Management, 18(1), 93-116.

Ferris, G. R., Munyon, T. P., Basik, K., Buckley, M. R. (2008). The performance evaluation context: Social, emotional, cognitive, political, and relationship components. Human Resource Management Review, 18, 146-163.

Ferris, G. R., Russ, G. S., \& Fandt, P. M. (1989). Politics in organizations. In R. A. Rosenfeld, Impression management in the organization (pp. 143-170). Hillside, NJ: Erlbaum.

Gandz, J., \& Murray, V. V. (1980). The experience of workplace politics. Academy of Management journal, 23(2), 237-251.

Hershcovis, M. (2011). 'Incivility, social undermining, bullying.. oh my!”: A call to reconcile constructs within workplace aggression research. Journal of Organizational Behavior, 32(3), 499-519.

Kabat-Farr, D., Cortina, L. M., \& Marchiondo, L. A. (2018). The emotional aftermath of incivility: Anger, guilt, and the role of organizational commitment. International Journal of Stress Management, 25(2), 109128.

Kacmar, K.M. \& Carlson, D.S. (1997). Future validation of the perceptions of politics scale (POPS): A multiple sample investigation. Journal of Management, 23, 627-658

Lange, J., Weidman, A. C., \& Crusius, J. (2018). The painful duality of envy: Evidence for an integrative theory and a meta-analysis on the relation of 
envy and schadenfreude. Journal of Personality and Social Psychology, 114(4), 572-598.

Lee, K., \& Duffy, M. K. (2019). A functional model of workplace envy and job performance: When do employees capitalize on envy by learning from envied targets? Academy of Management Journal, 62(4), 1085-1110.

Maslach, C., Schaufeli, W., \& Leiter, M. p. (2001). Annual Review of Psychology, 52(1), 397-422.

Matsela, M.A., \& Kirsten, G.J.C. (2014). Teachers' experiences and impact of workplace bullying on their health in Lesotho. Psychology Research, 4(6), 479-491.

McPhee, S. D., \& Townsend, L. J. (1992). A study of organizational commitment and job satisfaction among Air Force occupational therapy officers. Military Medicine, 157(3), 117-121.

Miller, B. K., Rutherford, M. A., \& Kolodinsky, R. W. (2008). Perceptions of organizational politics: A meta-analysis of outcomes. Journal of Business and Psychology, 22(3), 209-222.

Preacher, K. J., \& Hayes, A. F. (2004). SPSS and SAS procedures for estimating indirect effects in simple mediation models. Behavior Research Methods, Instruments, \& Computers, 36(4), 717-731.

Rich B. L., Lepine J. A., \& Crawford E. R. (2010). Job engagement: Antecedents and effects on job Performance. Academy of Management Journal, 53(3), $617-635$.

Robinson, S. L. \& O'Leary-Kelly, A. M. (1998). Monkey see, monkey do: the influence of work groups on the antisocial behavior of employees. Academy of Management Journal, 41(6), 658-672.

Saks, A. (2006). Antecedents andconsequences of employee engagement. Journal of Managerial Psychology, 21(7), 600-619.

Salin, D. (2002). Bullying and organisational politics in competitive and rapidly changing work environments. International Journal of Management and Decision, 4(1), 35-46. 
Shrout, P. E., \& Bolger, N. (2002). Mediation in experimental and nonexperimental studies: new procedures and recommendations. Psychological Methods, 7(4), 422.

Smith, P. K., Mahdavi, J., Carvalho, M., Fisher, S., Russell, S., \& Tippett, N. (2008). Cyberbullying: its nature and impact in secondary school pupils. Journal of Child Psychology and Psychiatry, 49(4), 376-385.

Smith, P. K. (2012). Cyberbullying and cyber aggression. In S. R. Jimerson, A. B. Nickerson, M. J. Mayer, \& M. J. Furlong (Eds.), Handbook of school violence and school safety: International research and practice (p. 93103). Routledge/Taylor \& Francis Group.

Smith, R. H. (2000). Assimilative and contrastive emotional reactions to upward and downward social comparisons. In \&. L. J. Suls, Handbook of social comparison: Theory and research. Dordrecht, the Netherlands: Kluwer Academic Publishers.

Spector, P. E. (2014). Job Satisfaction Survey, JSS Translations. Retrieved from http://shell.cas.usf.edu/ pspector/scales/jsstranslate.html

Tai, K., Narayanan, J., \& McAllister, D. J. (2012). Envy as pain: Rethinking the nature of envy and its implications for employees and organizations. The Academy of Management Review, 37, 107-129.

Tokunaga, R. (2010). Following you home from school: A critical review and synthesis of research on cyberbullying victimization. Computers in Human Behaviour, 26(3), 277-287.

Trépanier, S. G., Fernet, C., Austin, S., \& Boudrias, V. (2016). Work environment antecedents of bullying: A review and integrative model applied to registered nurses. International Journal of Nursing Studies, 55, 85-97.

Van de Ven, N., Zeelenberg, M., \& Pieters, R. (2009). Leveling up and down: The experiences of benign and malicious envy. Emotion, 9, 419-429.

Vecchio, R. P. (2000). Negative emotion in the workplace: Employee jealousy and envy. International Journal of Stress Management, 7(3), 161-179. 
Zapf, D. (1999). Organisational, work group related and personal causes of mobbing/bullying at work. International Journal of Manpower, 20(1-2), $70-85$

Zapf, D. \& Warth, K. (1997). Mobbing: Subtile Kriegsführung am Arbeitsplatz. Psychologie Heute, 20-25,28-29.

Zhao, X., Lynch Jr, J. G., \& Chen, Q. (2010). Reconsidering Baron and Kenny: Myths and truths about mediation analysis. Journal of Consumer Research, 37(2), 197-206.

\section{Citation of this Article:}

Malik, S. Z., \& Malhi, J. I. (2020) Envy at Workplace: Examining its Sequential Effect on Cyberbullying, Organizational Politics and Job Satisfaction in University Teachers in Pakistan. International Journal of Innovation in Teaching and Learning (IJITL), 6(2), 128-145. 